\title{
Biometric Predictability in Combined Cataract Surgery and Ahmed Glaucoma Valve Implantation Depending on Tube Position
}

\author{
Ana Marta (iD) ${ }^{1,2}$ \\ João Coelho (iD' \\ Rita Vieira (ID) \\ Ana Figueiredo' \\ Rita Reis' \\ Isabel Sampaio' \\ Maria João Menéres ${ }^{1,2}$ \\ Pedro Menéres $\mathbb{I D}^{1,2}$ \\ 'Department of Ophthalmology, Centro \\ Hospitalar e Universitário do Porto, \\ Oporto, Portugal; ${ }^{2}$ Instituto de Ciências \\ Biomédicas Abel Salazar, Oporto, \\ Portugal
}

Purpose: To compare the predictability of biometric results in patients undergoing cataract surgery combined with Ahmed glaucoma valve (AGV) implantation according to tube position.

Methods: A retrospective cohort study was performed in patients who underwent phacoemulsification surgery combined with AGV implantation with the tube in posterior (group PC) and anterior (group AC) chamber, between November 2012 and April 2020. The main outcome was the mean biometric prediction error, according to tube position, using different formulas.

Results: The study included 49 eyes of 36 patients, 23 eyes in group PC and 26 eyes in group AC. Gender $(p=0.774)$, age $(p=0.822)$, type of glaucoma $(p=0.168)$, preoperative correct distance visual acuity $(\mathrm{p}=0.139)$, axial length $(\mathrm{p}=0.765)$, anterior chamber depth $(\mathrm{p}=0.351)$, keratometry $(\mathrm{p}=0.577)$ and intraocular lens power $(\mathrm{p}=0.608)$ were similar between groups. Only preoperative intraocular pressure was higher in group $\mathrm{PC}(\mathrm{p}=0.005)$. The mean prediction errors using Haigis, SRK/T, Hoffer Q, Holladay 1, Barrett Universal II, Kane and Hill RBF formulas were all positive in group PC (hyperopic) and all negative (myopic) in group AC. In group PC, there was no significant difference in prediction error between these formulas $(p>0.05)$. In group $A C$, the formula with the worst prediction error was Haigis ( $\mathrm{p}=0.001)$, and the best was Barrett Universal II $(\mathrm{p}=0.043)$.

Conclusion: The biometric predictability and expected final refraction in phacoemulsification surgery combined with AGV implantation are modified by the position of the tube.

Keywords: glaucoma, Ahmed valve, cataract, phacoemulsification, biometry

\section{Introduction}

Glaucoma drainage implants have been used for a long time, and are particularly indicated in refractory glaucomas, when the risk of trabeculectomy failure is high, such as neovascular glaucoma, uveitic glaucoma, congenital glaucoma ${ }^{1}$ and transthyretin-related familial amyloidotic polyneuropathy (TTR-FAP) secondary glaucoma. Bayer and Önol ${ }^{2}$ demonstrated similar success rates for Ahmed glaucoma valve (AGV) tube insertion through the anterior chamber angle compared to AGV tube insertion through the ciliary sulcus.

If cataract and refractory glaucoma coexist, combined phacoemulsification and glaucoma drainage implant surgery is an option. This combined procedure has some advantages: good visual rehabilitation with simultaneous improved intraocular pressure (IOP) control; less risk of failure compared with conventional filtering
Correspondence: Ana Marta

Department of Ophthalmology, Centro Hospitalar e Universitário do Porto, Largo do Prof. Abel Salazar, Porto, 4099-00I. Portugal

Email analuisamarta2@gmail.com 
surgery; single surgical intervention with reduced anaesthesia and surgical time for the patient; reduced risk of repeated surgery; and reduced overall cost of care to the health system. ${ }^{3}$

The efficacy of IOP lowering has been well documented with the combined approach. Concerning refractive outcomes, these are still poorly defined. ${ }^{4}$ There are some studies related to phacoemulsification surgery combined with trabeculectomy, ${ }^{5}$ Kahook Dual Blade goniotomy $^{6}$ and endoscopic cyclophotocoagulation. ${ }^{7}$ Tzu et al have published refractive outcomes of combined cataract and glaucoma surgery, but did not distinguish between phacoemulsification surgery combined with trabeculectomy and phacoemulsification surgery combined with glaucoma drainage implants. ${ }^{4}$ More recently, Kwon and Sung included refractive outcomes in addition to the IOP control outcomes of phacoemulsification surgery combined with AGV implantation, but all eyes had the tube inserted into the anterior chamber and they only reported the absolute refractive error among the four formulas, so that it was not possible to see whether there is any tendency towards a myopic or hyperopic shift. ${ }^{8}$ Currently, there are no published studies in the literature with refractive outcomes discriminating on the basis of tube position. This study aims to evaluate the predictability of biometric results in patients undergoing cataract surgery combined with AGV implantation according to tube position.

\section{Materials and Methods Study Design}

A retrospective consecutive case-series study was performed, including patients with a diagnosis of glaucoma who underwent phacoemulsification surgery combined with AGV implantation with the tube in posterior (group PC) and anterior (group AC) chamber, in the Ophthalmology Department of Centro Hospitalar e Universitário do Porto, between November 2012 and April 2020. This study was conducted following the tenets of the Declaration of Helsinki (1964). The authors ensured that all patients' anonymity was carefully protected. Informed consent was signed for all procedures and the study followed all the guidelines required by the local ethics committee. Approval was obtained from the "Departamento de Ensino, Formação e Investigação" (DEFI).

\section{Participants}

The inclusion criteria for both groups were patients with refractory glaucoma and cataract who underwent combined phacoemulsification with AGV implantation. Indications for combined surgery in our institution included cataract and uncontrolled IOP despite maximum tolerated topical therapy with documented glaucoma progression, or previously failed glaucoma surgery. Patients with corneal opacity, irregular astigmatism, pterygium, prior corneal, refractive or sclera buckling surgeries, absence of IOLMaster biometry, amblyopia and any intraoperative complications were excluded.

\section{Parameters}

The following variables were analyzed:

- -demographic characteristics (gender, age and subtype of glaucoma);

- -previous ocular surgeries (vitrectomy and glaucoma surgeries);

- -type of intraocular lens (IOL) used and biometric characteristics (axial length, anterior chamber depth, keratometry, corneal astigmatism and respective axis and refractive target for the IOL power used by different formulas);

- -preoperative and postoperative evaluation at two to three months [corrected distance visual acuity (CDVA), IOP, equivalent spherical refraction, cylinder refraction and axis].

Intraocular lens power was calculated by IOL Master ${ }^{\circledR}$ 500 or IOL Master ${ }^{\circledR} 700$ devices (Carl-Zeiss Meditec, Germany). For numerical analysis, Snellen visual acuity was converted to the logarithm of the minimum angle of resolution $(\log M A R)$ values. Intraocular pressure was measured using Goldmann's applanation tonometry. Postoperative evaluation was considered at two to three months after surgery to guarantee the refractive stability and to avoid refractive parameters in the hypertensive phase when it occurred. The main outcome measure was the biometric prediction error according to tube position in patients undergoing cataract surgery combined with AGV implantation.

\section{Surgical Procedure}

All surgical procedures were carried out by four experienced glaucoma surgeons. In all eyes, the AcrySof IQ SN60WF IOL 
(Alcon Laboratories, Fort Worth, TX, USA) and the FP7 model AGV (New World Medical ${ }^{\circledR}$, Rancho Cucamonga, CA, USA) were used. Under subtenonian anesthesia with lidocaine $2 \%$, combined surgery was performed according to the following technique: a limbal-based conjunctival incision was made to create a conjunctival flap between two recti muscles in the superotemporal quadrant; cauterization of episcleral vessels; priming of the $\mathrm{AGV}$ by introducing balanced salt solution in the tube; placement of the plate 8 to $10 \mathrm{~mm}$ posterior to the corneal limbus and sclera fixation with 8-0 nylon; scleral flap creation (two-thirds thickness); AC paracentesis with a $15^{\circ}$ scalped, injection of viscoelastic substance and $2.4 \mathrm{~mm}$ clear cornea incision; flap creation and continuous circular capsulorhexis completed with the capsule forceps; hydrodissection; phacoemulsification of cataract; complete cortex removal; injection of a foldable intraocular lens; cutting the tube to a bevel-shaped angle of $30^{\circ}$, creating a route $1-3 \mathrm{~mm}$ posteriorly to the corneoscleral limbus, parallel to the iris with a 23-gauge needle; inserting the tube in $\mathrm{AC}$ or PC (in the ciliary sulcus) (according to surgeon preference); suture of the tube to the sclera with $8-0$ nylon and covering with an scleral flap sutured with 10-0 nylon; finally, the conjunctiva was closed with 10-0 nylon or 8-0 vicryl (according to surgeon preference); viscoelastic substance removal, corneal incision hydration and a subconjunctival injection of cefazolin and dexamethasone was performed.

In the postoperative period, all patients were treated with topical antibiotics for eight days, oral and topical steroids at weaning and non-steroidal anti-inflammatory drops for six months.

\section{Statistical Analysis}

The statistical analysis was performed using the SPSS program (SPSS Statistics, version 22.0 for Windows, SPSS Inc., IBM, Somers, NY). The normality of the variables was evaluated using the Shapiro-Wilk test. For preoperative and postoperative analysis, the Wilcoxon test and pairedsample $t$-test were used. The comparison between independent continuous variables was performed using the Student's $t$-test and the Mann-Whitney test. The Fisher exact test was used for nominal scaled data. $\mathrm{P}$ values less than 0.05 were considered statistically significant.

\section{Results}

\section{Demographic Data}

This study included 36 patients (49 eyes), 41.7\% male and $58.3 \%$ female, aged 30 to 76 years, with a mean age of
$54.9 \pm 8.3$ years $(\mathrm{y})$ at the time of AGV implantation combined with cataract surgery.

Group PC included 23 eyes, 95.7\% diagnosed with TTR-FAP secondary glaucoma and $4.3 \%$ with pseudoexfoliation (PXF) glaucoma. The average age was $55.2 \pm 5.2$ years and $61 \%$ were female. One eye $(4.3 \%)$ had trabeculectomy before AGV implantation. Vitrectomy pars plana had been performed previously in 13 eyes (56.5\%).

Group AC included 26 eyes, 73.1\% diagnosed with TTR-FAP secondary glaucoma, $11.5 \%$ with PXF glaucoma, $11.5 \%$ with uveitic glaucoma and $3.8 \%$ with secondary glaucoma following vitreoretinal surgery. The average age was $54.7 \pm 10.4$ years and $54 \%$ were female. Four eyes (15.4\%) had glaucoma surgeries before AGV implantation: trabeculectomy in two eyes; EX-PRESS ${ }^{\circledR}$ implant in one eye; trabeculectomy and cyclophotocoagulation in one eye. Vitrectomy pars plana had been performed previously in 14 eyes $(53.8 \%)$.

There were no statistically significant differences in the comparison of age $(\mathrm{p}=0.822)$, gender $(\mathrm{p}=0.774)$, type of glaucoma $(p=0.168)$ and previous glaucoma surgery $(p=0.353)$ and vitrectomy $(\mathrm{p}=0.540)$ between the groups (Table 1$)$. Concerning biometric values, both groups had similar axial length $(\mathrm{p}=0.765)$, anterior chamber depth $(\mathrm{p}=0.351)$ and mean keratometry $(p=0.577)$. The IOL diopters used were also similar $(\mathrm{p}=0.608)$ between the groups (Table 1$)$.

\section{Refractive Outcomes}

\section{Corrected Distance Visual Acuity and Refraction}

Preoperative CDVA improved from $0.4 \pm 0.3 \log$ MAR to 0.3 $\pm 0.1 \log \mathrm{MAR}$ in group $\mathrm{PC}$ and from $0.4 \pm 0.3 \log \mathrm{MAR}$ to 0.2 $\pm 0.0 \log$ MAR in group AC (Table 2). Preoperative and postoperative CDVA was similar ( $\mathrm{p}=0.139$ and $\mathrm{p}=0.675$, respectively) in both groups. The absolute final equivalent spherical refraction value was higher $(\mathrm{p}=0.034)$ in group $\mathrm{AC}(\mu=0.7$ $\pm 0.7)$ than in group PC $(\mu=0.1 \pm 1.2)$, without statistically significant differences in final cylinder refraction value $(\mathrm{p}=0.067)$. The difference between postoperative and preoperative astigmatism (induced astigmatism) was similar $(p=0.544)$ between-group $\mathrm{PC}(\mu=0.9 \pm 1.8)$ and group $\mathrm{AC}$ $(\mu=0.6 \pm 1.4)$.

\section{Biometric Predictability}

The mean prediction error using Haigis, SRK/T, Hoffer Q, Holladay 1, Barrett Universal II, Kane and Hill RBF formulas were all positives (more hyperopic) in group $\mathrm{PC}$ and all negatives (more myopic) in group $\mathrm{AC}$ (Table 2). In group $\mathrm{PC}$, there was no significant 
Table I Demographic Data

\begin{tabular}{|c|c|c|c|}
\hline & Group PC $(n=23)$ & Group AC $(n=26)$ & $\mathbf{P}$ \\
\hline Gender: male/female (\%) & $39.1 \% / 60.9 \%$ & $46.2 \% / 53.8 \%$ & 0.774 \\
\hline Age, y (mean $\pm S D)$ & $55.2 \pm 5.2$ & $54.7 \pm 10.4$ & 0.822 \\
\hline \multicolumn{4}{|l|}{ Type of glaucoma (\%) } \\
\hline FAP & $22 / 23(95.7 \%)$ & $19 / 26(73.1 \%)$ & 0.168 \\
\hline PXF & $\mathrm{I} / 23(4.3 \%)$ & $3 / 26(11.5 \%)$ & \\
\hline Uveitic & - & $3 / 26(11.5 \%)$ & \\
\hline After vitrectomy pars plana & - & $1 / 26(3.8 \%)$ & \\
\hline \multicolumn{4}{|l|}{ Ocular surgeries pre-AGV (\%) } \\
\hline Glaucoma surgery & $\mathrm{I} / 23(4.3 \%)$ & $4 / 26(15.4 \%)$ & 0.353 \\
\hline Vitrectomy & I3/23 (56.5\%) & $14 / 26(53.8 \%)$ & 0.540 \\
\hline \multicolumn{4}{|l|}{ Biometric values (mean $\pm S D$ ) } \\
\hline Axial length, $\mathrm{mm}$ & $23.3 \pm 0.6$ & $23.4 \pm 1.4$ & 0.765 \\
\hline $\mathrm{ACD}, \mathrm{mm}$ & $3.1 \pm 0.3$ & $3.0 \pm 0.4$ & 0.351 \\
\hline Keratometry, D & $44.7 \pm 1.3$ & $44.4 \pm 2.2$ & 0.577 \\
\hline IOL dioptre used (mean $\pm S D)$ & $21.0 \pm 1.7$ & $21.3 \pm 3.0$ & 0.608 \\
\hline
\end{tabular}

Abbreviations: ACD, anterior chamber depth; AGV, Ahmed glaucoma valve; D, dioptre; FAP, familial amyloid polyneuropathy; IOL, intraocular lens; PXF, pseudoexfoliation; SD, standard deviation; $y$, years.

difference in prediction error between these formulas ( $\mathrm{p}>0.05)$. In group $\mathrm{AC}$, the formula with the worst prediction error was Haigis $(\mathrm{p}=0.001)$ and the best was Barrett Universal II $(\mathrm{p}=0.043)$ (Figure 1). The mean difference in target and postoperative refraction spherical equivalent (refractive surprise) was similar between eyes with biometric measures using the IOL Master ${ }^{\circledR}$ 500 device and IOL Master ${ }^{\circledR} 700$ device within group $\mathrm{PC}(\mathrm{p}=0.878)$ and group $\mathrm{AC}(\mathrm{p}=0.490)$.

Within $\pm 0.5 \mathrm{D}$, the biometry prediction error (spherical equivalent) was $53.1 \%$ (26/49), and within $\pm 1 \mathrm{D}$, it was $71.4 \%(35 / 49)$. There were 14 cases with greater than $\pm 1 \mathrm{D}$ of refractive surprise, eight in group PC (four myopic and four hyperopic) and six in group $\mathrm{AC}$ (five myopic and one hyperopic). There were 23 cases with greater than $\pm 0.5 \mathrm{D}$ of refractive surprise, 13 in group PC (six myopic and seven hyperopic) and 10 in group $\mathrm{AC}$ (eight myopic and two hyperopic). Figure 2 presents the refractive surprise by groups. The biometry prediction error within $-1 \mathrm{D}$ and $+0.5 \mathrm{D}$ was achieved in $63 \%$ (31/49) of patients.

As presented in Table 3, in patients with refractive surprise greater than $\pm 1 \mathrm{D}$, no ocular or patient characteristics were identified as a significant risk factor, including biometric parameters.

\section{Discussion}

Currently, with advancing techniques, the achievement of more predictable refractive outcomes has been accompanied by an increase in patients' expectations of a good visual outcome, ${ }^{9}$ even in patients with other ocular comorbidities. Manoharan et al have demonstrated that patients with a diagnosis of glaucoma are more likely to have a refractive surprise and/or worse visual outcome after phacoemulsification cataract surgery. ${ }^{10}$ Combination cataract and glaucoma procedures may increase refractive surprise as well. ${ }^{6}$ Our study indicated biometric predictability differences depending on tube position in combined cataract surgery and AGV implantation.

Most of the modern biometric formulas are based on the theoretical equation formulated by Fedorov and its modifications. ${ }^{11}$ We included in our analysis the prediction error calculated by third- and newer generation formulas, which attempt to calculate the effective lens position more accurately. Nevertheless, multiple variables are likely to influence predictability and accuracy of refraction other than the position of AGV tube (AC vs PC) in combined surgery. These factors include pre-operative refractive status including high myopia or hyperopia, amount and type of pre-existing astigmatism, the status of zonules (laxity as in pseudoexfoliation, high myopia post vitrectomised 
Table 2 Surgical Outcomes

\begin{tabular}{|c|c|c|c|}
\hline & Group PC $(n=23)($ Mean $\pm S D)$ & Group AC $(n=26)($ Mean $\pm S D)$ & $\mathbf{P}$ \\
\hline Preoperative CDVA, logMAR & $0.4 \pm 0.3$ & $0.4 \pm 0.3$ & 0.139 \\
\hline Postoperative CDVA, logMAR & $0.3 \pm 0.1$ & $0.2 \pm 0.0$ & 0.675 \\
\hline Preoperative IOP, $\mathrm{mmHg}$ & $29.9 \pm 7.5$ & $24.5 \pm 5.2$ & 0.005 \\
\hline Postoperative IOP, $\mathrm{mmHg}$ & $16.8 \pm 5.4$ & $\mid 7.1 \pm 4.7$ & 0.839 \\
\hline \multicolumn{4}{|l|}{ Prediction error, D } \\
\hline Haigis & $0.2 \pm 1.2$ & $-0.6 \pm 0.7$ & 0.015 \\
\hline $\mathrm{SRK} / \mathrm{T}$ & $0.1 \pm 1.1$ & $-0.4 \pm 0.8$ & 0.056 \\
\hline Hoffer & $0.2 \pm 1.2$ & $-0.4 \pm 0.9$ & 0.034 \\
\hline Holladay I & $0.2 \pm 1.1$ & $-0.4 \pm 0.8$ & 0.049 \\
\hline Barrett & $0.2 \pm 1.2$ & $-0.3 \pm 0.8$ & 0.065 \\
\hline Kane & $0.2 \pm 1.2$ & $-0.4 \pm 0.8$ & 0.042 \\
\hline HillRBF & $0.2 \pm 1.2$ & $-0.4 \pm 0.8$ & 0.055 \\
\hline Preoperative Equivalent Spherical, D & $-1.2 \pm 3.2$ & $-1.7 \pm 3.6$ & 0.678 \\
\hline Final Equivalent Spherical, D & $-0.1 \pm 1.2$ & $-0.7 \pm 0.7$ & 0.034 \\
\hline K2-KI, D & $-1.4 \pm 1.0$ & $-1.7 \pm 1.3$ & 0.376 \\
\hline Final cylinder refraction, D & $-0.5 \pm 1.3$ & $-1.1 \pm 0.9$ & 0.067 \\
\hline Preoperative Corneal astigmatism axis, ${ }^{\circ}$ & $120.3 \pm 60.8$ & $94.5 \pm 66.1$ & 0.164 \\
\hline Final cylinder axis, ${ }^{\circ}$ & $113.0 \pm 69.2$ & $108.4 \pm 58.1$ & 0.806 \\
\hline
\end{tabular}

Note: Bold text represents statistically significant $P$ value.

Abbreviations: CDVA, corrected distance visual acuity; D, dioptre; IOP, intraocular pressure; SD, standard deviation.

eyes), as well as the status of scleral rigidity. When placing the AGV plate on the sclera, the use and tightness of nonabsorbable suture to anchor plate over sclera are equally important factors to address the final status of the refraction. In the same manner, the construction and configuration of the scleral tunnel, number, and types of sutures applied to secure tunnel are equally crucial to set accuracy in the refractive status following post combined AGV and phacoemulsification surgery. Hence, IOL power calculation is likely to have unpredicted variations in the abovementioned scenarios.

We verified that the mean prediction errors using Haigis, SRK/T, Hoffer Q, Holladay 1, Barrett Universal II, Kane and Hill RBF formulas were all positive (more hyperopic) in group PC and all negative (more myopic) in group AC. The axial length, anterior chamber depth, keratometry, lens thickness and white-to-white parameter were not potential risk factors for refractive surprise overall in our sample (Table 3).

Concerning group PC, we suspect that a change in the effective lens position is the most likely contributor to the observed refractive surprise, although we have no imaging to support this. The tube in group PC may displace the IOL posteriorly and may cause an overall hyperopic shift. The other hypothesis for the overall hyperopic shift is the possibility of the shortening of the axial length, demonstrated to be significant by Miraftabi et al due to the decrease in IOP. ${ }^{12}$ In fact, preoperative IOP was higher in group PC and, for this reason, this group had a higher decrease in IOP. However, we did not analyse the postoperative axial lengths to support this, because it is a retrospective study and this measure is not included in the follow-up routine after this surgery.

Concerning group $\mathrm{AC}$, the tube placed in $\mathrm{AC}$ will not change presumed refraction by the virtue of its position in AC unless occur anteriorly directed mechanical tractional forces on the lens-iris diaphragm moving the lens position forward. Another possibility is the shallowing of the anterior chamber depth, even though we have no pre and postoperative anterior chamber depth measurements to support this. The shallowing of the anterior chamber depth is a frequent condition after glaucoma procedures. We know that if there is a reduction in effective lens position as the preoperative anterior chamber depth 


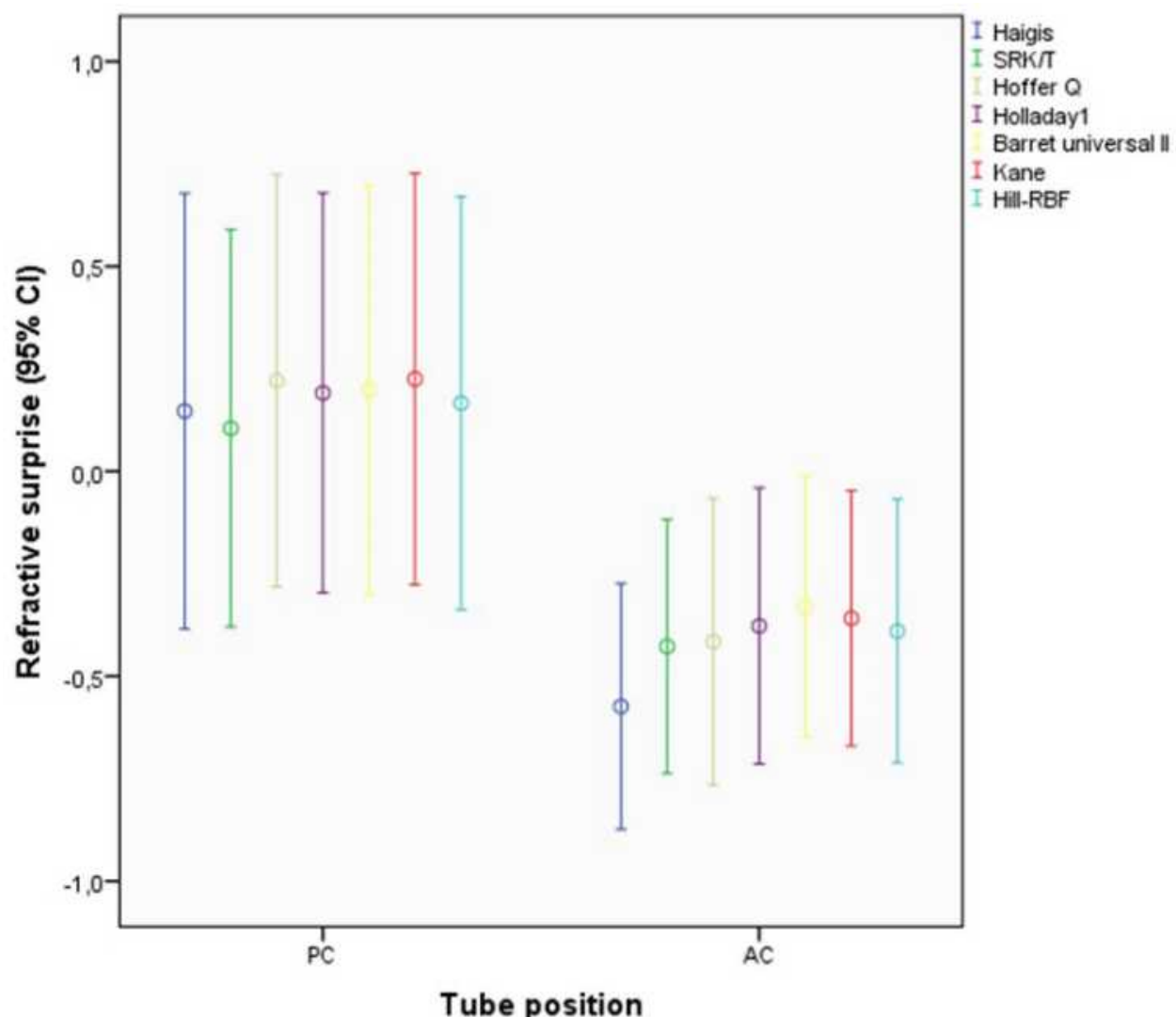

Figure I Mean predictive error using Haigis, SRK/T, Hoffer Q, Holladay I, Barrett Universal II, Kane and Hill RBF formulas by tube position groups. Error bars indicate confidence interval of $95 \%$.

Abbreviations: PC, tube in posterior chamber; $\mathrm{AC}$, tube in anterior chamber.
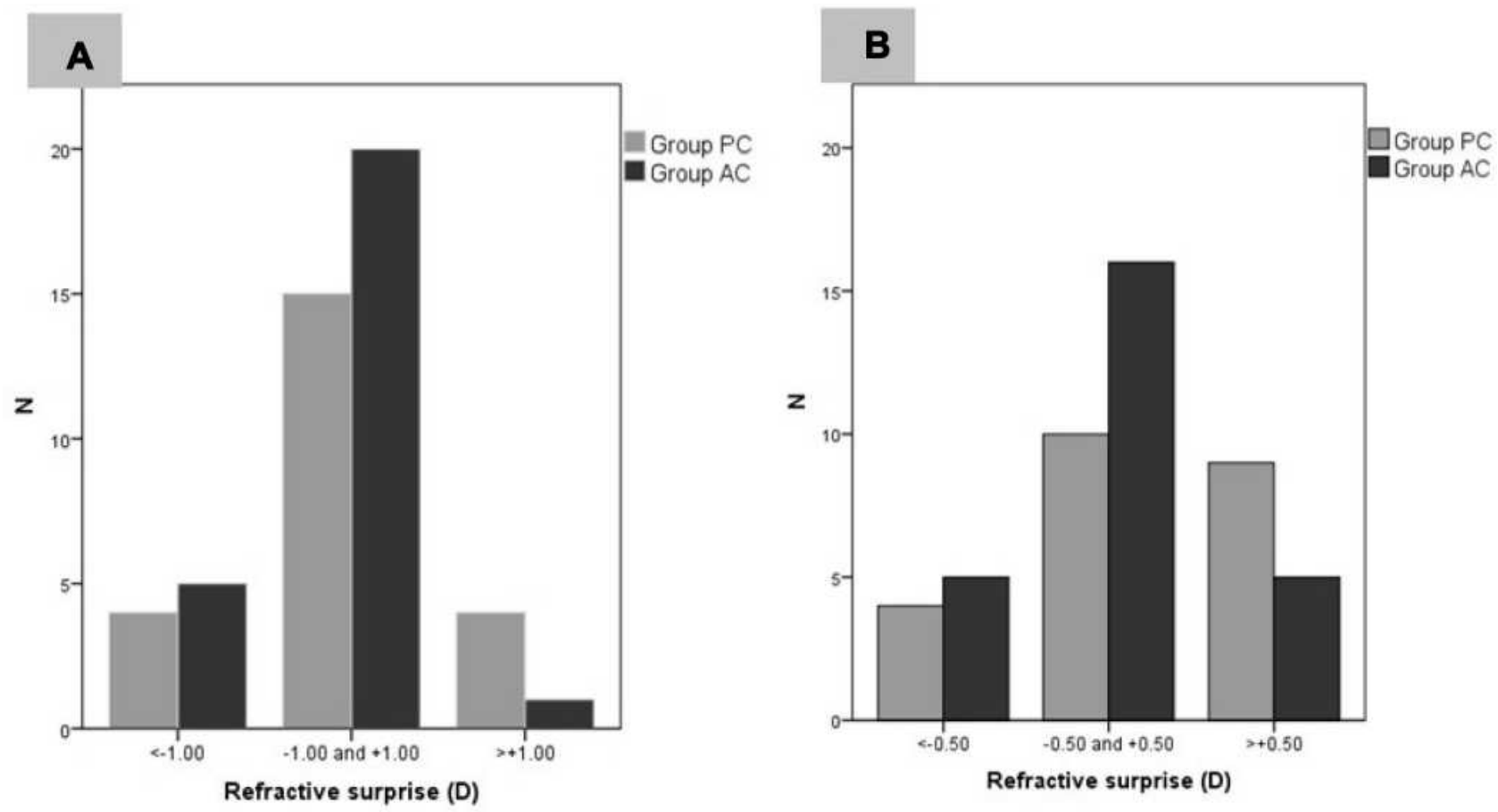

Figure 2 Refractive surprise in patients with tube in posterior $(\mathrm{PC})$ and anterior $(\mathrm{AC})$ chamber. Biometry prediction error within $\pm 1.00 \mathrm{D}(\mathbf{A})$ and $\pm 0.50 \mathrm{D}(\mathbf{B})$. 
Table 3 Potential Risk Factors of Refractive Surprise

\begin{tabular}{|c|c|c|c|}
\hline & $\begin{array}{l}\text { Refractive Surprise Greater Than } \pm \text { ID } \\
\qquad \mathrm{N}=14\end{array}$ & $\begin{array}{l}\text { Refractive Surprise Lower Than } \pm \text { ID } \\
\qquad N=35\end{array}$ & $\mathbf{P}$ \\
\hline \multicolumn{4}{|l|}{ Tube position (\%) } \\
\hline PC & $8 / 14(57.1 \%)$ & I5/35 (42.9\%) & 0.528 \\
\hline$A C$ & $6 / 14(42.9 \%)$ & $20 / 35(57.1 \%)$ & \\
\hline Previous vitrectomy (\%) & $8 / 14(57.1 \%)$ & 19/35 (54.3\%) & 1.000 \\
\hline Previous glaucoma surgery (\%) & $2 / 14(14.3 \%)$ & $3 / 35(8.6 \%)$ & 0.616 \\
\hline Preoperative CDVA, logMAR (mean $\pm S D)$ & $0.5 \pm 0.4$ & $0.4 \pm 0.3$ & 0.130 \\
\hline Preoperative IOP, $\mathrm{mmHg}($ mean $\pm \mathrm{SD})$ & $27.9 \pm 6.6$ & $26.7 \pm 7.0$ & 0.585 \\
\hline Postoperative IOP, $\mathrm{mmHg}($ mean $\pm \mathrm{SD})$ & $18.3 \pm 6.2$ & $16.5 \pm 4.6$ & 0.281 \\
\hline Axial length, mm (mean $\pm S D)$ & $23.4 \pm 0.6$ & $23.4 \pm 1.3$ & 0.951 \\
\hline Anterior chamber depth, mm (mean $\pm S D)$ & $3.0 \pm 0.4$ & $3.1 \pm 0.4$ & 0.484 \\
\hline Keratometry, D (mean $\pm S D)$ & $44.6 \pm 2.0$ & $44.6 \pm 1.3$ & 0.990 \\
\hline Lens thickness, $\mathrm{mm}(\operatorname{mean} \pm \mathrm{SD})$ & $4.4 \pm 0.5$ & $4.5 \pm 0.4$ & 0.710 \\
\hline White-to-white, mm (mean $\pm S D)$ & $11.8 \pm 0.3$ & $11.8 \pm 0.3$ & 0.826 \\
\hline
\end{tabular}

Abbreviations: AC, anterior chamber; CDVA, corrected distance visual acuity; D, dioptre; IOP, intraocular pressure; PC, posterior chamber; SD, standard deviation.

decreases, lower IOL power is needed for achieved emmetropia, ${ }^{13}$ explaining the myopic shift verified in this group.

Within $\pm 1 \mathrm{D}$ biometry, the prediction error was $71.4 \%$ (35/49), higher than the $51.8 \%$ reported by Muallem et al with cataract surgery after trabeculectomy, ${ }^{5}$ but lower than the $88.8 \%$ reported by Manoharan et al with cataract surgery in glaucoma patients (without glaucoma surgery), ${ }^{10}$ and the $94 \%$ reported by EUREQUO with standard cataract surgery. ${ }^{14}$ Within $\pm 0.5 \mathrm{D}$, the biometry prediction error was $53.1 \%$ (26/49), higher than the $48.4 \%$ reported by Kang et al with cataract surgery with endoscopic cyclophotocoagulation, ${ }^{15}$ but lower than the $59.7 \%$ reported by Manoharan et al with cataract surgery of glaucoma patients (without glaucoma surgery) ${ }^{10}$ and the $72.7 \%$ reported by EUREQUO with standard cataract surgery. ${ }^{14}$

A biometry prediction error within $-1 \mathrm{D}$ and $+0.5 \mathrm{D}$ was achieved in $63 \%$ patients, slightly higher than the $57 \%$ reported by Kwon and Sung with cataract surgery combined with AGV implantation ${ }^{8}$ and slightly lower than the $74 \%$ reported by $\mathrm{Tzu}$ et al with combined cataract and glaucoma surgery. ${ }^{4}$

To our knowledge, this is the first study to document the effects of tube position on the biometric predictability of cataract surgery combined with AGV implantation. One of the strengths of this study is the use of different formulas (vergence and artificial intelligence-based formulas) to evaluate the prediction error. The major limitation of this study is its small sample size. However, a target population with an indication for cataract surgery combined with valve implantation is very limited. Often even studies that evaluate the effectiveness of controlling ocular tension in this surgery also end up including few patients, given the lower frequency of refractory glaucoma. Our hospital is a referral center for TTR-FAP; therefore, in our study, the most common refractory glaucoma was secondary to this pathology. ${ }^{16}$ This also explains that vitrectomy was previously performed in about half of the patients in our sample, due to vitreous opacities secondary to TTR-FAP. Post vitrectomy eyes may have variations in the presumed position of the IOL implant from the nodal point as well as it is expected to have more depth of anterior chamber due to fluidic vitreous. Findings from this highly specialized sample prone to having multiple ophthalmic abnormalities may not be generalizable to the population. Further limitations are as follows: the study's retrospective design and surgical procedures performed by four different surgeons. Despite being a retrospective and non-randomized 
study, patient and ocular demographics were similar between the two groups (Table 1). Studies with other devices and with larger sample sizes are needed for this population.

In addition to the refractive status, the position of the tube in the ciliary sulcus may also influence the amount of IOP control as this position of the tube is likely to release a significant amount of uveal pigments by the virtue of its placement site as well as of persistent mechanical touch of the tube over the posterior surface of the iris. This excessive dispersion of iris pigments may affect trabecular meshwork and increase the incidence of chronic inflammation as well as of early posterior capsular opacification. Nevertheless, the postoperative IOP was similar between AC and PC groups in our study. AGV tube placed in $\mathrm{AC}$ is considered as a preferred location in most of the cases, also by the facility of technique. In the case of combined AGV and cataract surgery which substantially increases AC depth, there are lesser possibilities of tube touch to the corneal endothelium. In very select cases where GDD surgery and vitrectomy are inevitable, despite diseased corneal endothelium, placement of the tube in the vitreous cavity can be another choice.

Overall, our study demonstrates a myopic shift in patients with the tube in the anterior chamber and a hyperopic shift in patients with the tube in the posterior chamber, after cataract surgery combined with AGV implantation. This must be taken into account when choosing the IOL power, regardless of the formula used, according to the tube implantation place. Based on the above-mentioned observations it is very difficult to establish and draw a logical conclusion to explain the different refractive outcomes according to the tube placement.

\section{Funding}

This research received no specific grant from any funding agency in the public, commercial, or not-for-profit sectors.

\section{Disclosure}

The authors declare that they have no conflicts of interest.

\section{References}

1. Valenzuela F, Browne A, Srur M, et al. Combined phacoemulsification and Ahmed glaucoma drainage implant surgery for patients with refractory glaucoma and cataract. J Glaucoma. 2016;25:162-166. doi:10.1097/IJG.0000000000000141

2. Bayer A, Önol M. Clinical outcomes of Ahmed glaucoma valve in anterior chamber versus ciliary sulcus. Eye. 2017;31:608-614. doi:10.1038/eye.2016.273

3. Chung AN, Aung T, Wang J-C, Chew PTK. Surgical outcomes of combined phacoemulsification and glaucoma drainage implant surgery for Asian patients with refractory glaucoma with cataract. $\mathrm{Am}$ J Ophthalmol. 2004;137:294-300. doi:10.1016/j.ajo.2003.08.036

4. Tzu JH, Shah CT, Galor A, Junk AK, Sastry A, Wellik SR. Refractive outcomes of combined cataract and glaucoma surgery. J Glaucoma. 2015;24:161-164. doi:10.1097/01.ijg.0000435773.20279.56

5. Muallem MS, Nelson GA, Osmanovic S, Quinones R, Viana M, Edward DP. Predicted refraction versus refraction outcome in cataract surgery after trabeculectomy. J Glaucoma. 2009;18:284-287. doi:10.1097/IJG.0b013e318184567b

6. Sieck EG, Capitena Young CE, Epstein RS, et al. Refractive outcomes among glaucoma patients undergoing phacoemulsification cataract extraction with and without Kahook Dual Blade goniotomy. Eye Vis. 2019;6. doi:10.1186/s40662-019-0153-2

7. Sheybani A, Saboori M, Kim JM, Gammon H, Lee AY, Bhorade AM. Effect of endoscopic cyclophotocoagulation on refractive outcomes when combined with cataract surgery. Can $J$ Ophthalmol. 2015;50:197-201. doi:10.1016/j.jcjo.2015.03.006

8. Kwon J, Sung KR. Factors Associated with outcomes of combined phacoemulsification and Ahmed glaucoma valve implantation. Korean J Ophthalmol. 2018;32:211-220.

9. Ferreira TB, Hoffer KJ, Ribeiro F, Ribeiro P, O’Neill JG. Ocular biometric measurements in cataract surgery candidates in Portugal. PLoS One. 2017;12:e184837. doi:10.1371/journal.pone.0184837

10. Manoharan N, Patnaik JL, Bonnell LN, et al. Refractive outcomes of phacoemulsification cataract surgery in glaucoma patients. $J$ Cataract Refract Surg. 2018;44:348-354. doi:10.1016/j.jcrs.2017.12.024

11. Fedorov SN, Kolinko AI, Kolinko AI. [A method of calculating the optical power of the intraocular lens]. Vestn Oftalmol. 1967;80:27-31. English.

12. Miraftabi A, Lotfi M, Nilforushan N, Abdolalizadeh P, Jafari S. Ocular biometric changes after Ahmed glaucoma valve implantation. Eur J Ophthalmol. 2021;31:120-124. doi:10.1177/ 1120672119889528

13. Miraftab M, Hashemi H, Fotouhi A, Khabazkhoob M, Rezvan F, Asgari S. Effect of anterior chamber depth on the choice of intraocular lens calculation formula in patients with normal axial length. Middle East Afr J Ophthalmol. 2014;21:307-311. doi:10.4103/0974-9233.142266

14. Lundström M, Dickman M, Henry Y, et al. Risk factors for refractive error after cataract surgery: analysis of 282811 cataract extractions reported to the European registry of quality outcomes for cataract and refractive surgery. J Cataract Refract Surg. 2018;44:447-452. doi:10.1016/j.jcrs.2018.01.031

15. Kang S, Luk S, Han H, et al. Refractive outcome of combined phacoemulsification and endoscopic cyclophotocoagulation. Int Ophthalmol. 2017;37:1311-1317. doi:10.1007/s10792-016-0411-4

16. Marta A, Vieira R, Figueiredo A, et al. Ahmed valve for secondary glaucoma in patients with hereditary transthyretin amyloidosis. Eye. 2021. doi:10.1038/s41433-021-01443-y 


\section{Publish your work in this journal}

Clinical Ophthalmology is an international, peer-reviewed journal covering all subspecialties within ophthalmology. Key topics include: Optometry; Visual science; Pharmacology and drug therapy in eye diseases; Basic Sciences; Primary and Secondary eye care; Patient Safety and Quality of Care Improvements. This journal is indexed on PubMed
Central and CAS, and is the official journal of The Society of Clinical Ophthalmology (SCO). The manuscript management system is completely online and includes a very quick and fair peer-review system, which is all easy to use. Visit http://www.dovepress.com/ testimonials.php to read real quotes from published authors. 